OPEN ACCESS

Edited by:

Chrishan S. Samuel,

Monash University,

Australia

Reviewed by:

Cees Korstanje,

Astellas Pharma (Europe),

Netherlands

Bing Hui Wang,

Monash University,

Australia

*Correspondence:

Yuming $\mathrm{Mu}$

mym1234@126.com

tThese authors have contributed equally to this work.

Specialty section:

This article was submitted to Cardiovascular and Smooth Muscle

Pharmacology,

a section of the journal

Frontiers in Pharmacology

Received: 11 November 2018

Accepted: 17 July 2019

Published: 21 August 2019

Citation:

Wang M, Hu R, Yang Y, Xiang L and Mu Y (2019) In Vivo Ultrasound

Molecular Imaging of SDF-1

Expression in a Swine Model of Acute Myocardial Infarction.

Front. Pharmacol. 10:899.

doi: 10.3389/fphar.2019.00899

\section{In Vivo Ultrasound Molecular Imaging of SDF-1 Expression in a Swine Model of Acute Myocardial Infarction}

\author{
Meng Wangt, Rong Hut, Yuanyuan Yang, Liping Xiang and Yuming $\mathrm{Mu}^{\text {* }}$ \\ Department of Echocardiography, First Affiliated Hospital, Xinjiang Medical University, Ürümqi, China
}

Background: Stem cell therapy of acute myocardial infarction (AMI) is proving to be a promising approach to repair the injured myocardia. The time window for stem cell transplantation is crucial yet difficult to determine since it produces different therapeutic effects at different times after myocardial infarction. Stromal cell-derived factor-1 (SDF- 1) plays a pivotal role in the mobilization, homing, proliferation, and differentiation of transplanted stem cells. Here, by using ultrasound molecular imaging via targeted microbubbles, we determined the dynamic expression of SDF-1 in a swine model of AMI in vivo.

Methods: Twenty-four miniswine were randomly selected for the control group and the AMI model group, which underwent ligation of the left anterior descending coronary artery (LAD). The AMI animals were randomly divided into six experimental groups according to the duration of the myocardial infarction. All animals were subjected to ultrasound molecular imaging through injections with targeted microbubbles $(T+T$ group) or nontargeted control microbubbles ( $T+C$ group). The values of the myocardial perfusion parameters $(A, \beta$, and $A \times \beta$ ) were determined using $Q$-Lab (Philips ultrasound, version 9.0), and the expression level of SDF-1 was analyzed by real-time polymerase chain reaction (RT-PCR).

Results: Our results showed that the expression of SDF-1 gradually increased and peaked at 1 week after AMI. The trend is well reflected by ultrasound molecular imaging in the myocardial perfusion parameters. The $A, \beta$, and $A \times \beta$ values correlated with SDF-1 in the $T+T$ group $(r=0.887,0.892$, and 0.942; $P<0.05)$. Regression equations were established for the relationships of the $A, \beta$, and $A \times \beta$ values $(X)$ with SDF-1 $(Y): Y=$ $0.699 X-0.6048, Y=0.4698 X+0.3282$, and $Y=0.0945 X+0.6685$, respectively $\left(R^{2}=\right.$ $0.772,0.7957$, and $0.8871 ; P<0.05)$.

Conclusions: Our finding demonstrated that ultrasound molecular imaging could be used to evaluate the expression dynamics of SDF-1 after AMI.

Keywords: SDF-1, targeted microbubbles, ultrasound molecular imaging, acute myocardial infarction, in vivo 


\section{INTRODUCTION}

Acute myocardial infarction (AMI), which is defined as myocardial cell death caused by prolonged ischemia, is one of the leading causes of cardiovascular disease mortality worldwide (Mozaffarian et al., 2016). Although various cardiovascular therapies, such as percutaneous coronary intervention, implantable defibrillators, and pharmacotherapeutics, have improved heart functions after AMI over recent decades, these treatments do not actively restore or regenerate the damaged myocardial tissue (Pfeffer and Braunwald, 1990; Kuraitis et al., 2011; Roger et al., 2012). The 1-year mortality rate (13\%) after an AMI and the resultant left ventricular (LV) systolic dysfunction remain high (Pfeffer et al., 2003).

Recently, replenishing lost cardiomyocytes using stem cell therapy was recognized to be an ideal strategy to retain cardiac function and prevent heart failure (Naaijkens et al., 2014). Several stem cells isolated from different tissue sources have been successfully utilized in therapy for post-AMI in preclinical and clinical studies. The first stem cells used were adult mesenchymal stem cells derived from bone marrow (Friedenstein et al., 1974). Zuk et al. showed that adipose-derived stem cells (ASCs), adult mesenchymal stem cells derived from adipose tissue, also have satisfactory effects (Zuk et al., 2002). There is evidence to demonstrate that both stem cell types can differentiate toward cardiomyocytes and endothelial cells and can be home to damaged tissues in vivo (Oswald et al., 2004; Pittenger and Martin, 2004; Boyle et al., 2010; Naaijkens et al., 2012). These adult mesenchymal stem cells may secrete growth factors and cytokines that can stimulate cardiovascular repair through a paracrine effect. Although stem cell-based treatments have shown great promise in the treatment of AMI, stem cell transplantation has different effects at different times after myocardial infarction (Friedenstein et al., 1974; Zuk et al., 2002; Oswald et al., 2004; Pittenger and Martin, 2004; Boyle et al., 2010; Naaijkens et al., 2012). Therefore, determining the optimal time at which stem cell transplantation should be performed is critical.

Stromal cell-derived factor-1 (SDF-1), a chemokine protein known as C-X-C motif chemokine 12 (CXCL12), has been shown to be involved in the mobilization, homing, proliferation, and differentiation of stem cells, with a particularly pivotal role in the homing of stem cells to injured myocardium (Huber et al., 2011; MacArthur et al., 2013; Schuh et al., 2014; Won et al., 2014). Studies have also revealed that the expression of SDF-1 differs throughout the acute period after myocardial injury (Boyle et al., 2011; Ghadge et al., 2011). Current techniques for evaluating SDF-1 expression involve in vitro investigations of tissue biopsies, which are complex and time-consuming and have limited clinical practicality, reflecting a difficult issue to address in a clinical setting. Fortunately, ultrasound molecular imaging provides another feasible approach to evaluate SDF-1 in local tissue after AMI. Targeted microbubbles can uniquely bind to SDF-1 molecules and allow imaging with a commercial ultrasound transducer in real time and in a noninvasive manner. Therefore, in this study, we attempted to develop a noninvasive detection technique to evaluate SDF-1 expression through ultrasound molecular imaging in vivo.

\section{MATERIALS AND METHODS}

\section{Animal Grouping}

Eight-month-old Chinese miniswine ( $27 \pm 3 \mathrm{~kg}$, both males and females) were obtained from the Laboratorial Animal Center of the First Affiliated Hospital of Xinjiang Medical University. All animals were vaccinated and dewormed, and they exhibited no signs of disease upon clinical examination before surgery. Three of the 24 miniswine were randomly selected as the control group $(\mathrm{n}=3$, sham operation group: the chest was opened, but ligation of the coronary artery was not performed), and the remaining 21 miniswine underwent ligation of the first diagonal branch of the left anterior descending coronary artery (LAD). Three animals died due to ventricular fibrillation within $50 \mathrm{~min}$ before the thoracic cavity was closed. Therefore, the remaining 18 miniswine that survived following LAD ligation were randomly divided into six experimental groups $(n=3)$ : the six groups were assigned based on six different time points ( 1 day, 3 days, 1 week, 2 weeks, 3 weeks, and 4 weeks) after AMI. All animals were injected with the targeted microbubble ultrasound contrast agent ( $\mathrm{T}+\mathrm{T}$ group) or the nontargeted ultrasound contrast agent $(\mathrm{T}+\mathrm{C}$ group $)$.

\section{AMI ANIMAL MODEL}

\section{Establishment of the AMI Model}

The miniswine were anesthetized using ketamine $(10-15 \mathrm{mg} / \mathrm{kg}$, intramuscularly) and atropine (25 $\mu \mathrm{g} / \mathrm{kg}$, intramuscularly), and the venous channels of the marginal ear vein were opened using a method published by Yang and Song (Song et al., 2012; Yang et al., 2013). During the operation, the swine were given intravenous anesthetics (ketamine hydrochloride and midazolam, $4.0 \mathrm{mg} / \mathrm{kg}$ bw). Mechanical respiratory ventilation was achieved via tracheal intubation after the administration of a suxamethonium chloride injection $(0.2 \mathrm{mg} / \mathrm{kg})$. In some cases, even after defibrillation, ventricular tachycardia or ventricular fibrillation may occur; therefore, the electrocardiogram, respiration, heart rate, and oxygen saturation were monitored using an electrocardiogram (ECG, USA, HP $\mathrm{Cm} \mathrm{XL+)} \mathrm{monitor} \mathrm{during} \mathrm{the} \mathrm{operation} \mathrm{and}$ were recorded every $15 \mathrm{~min}$. An extra defibrillation instrument was available as a precaution. Sublingual pieces of Betaloc 3 (mixed in saline solution after being ground into powder) were applied after anesthesia was induced, and intravenous lidocaine (at an infusion rate of $50 \mu \mathrm{g} / \mathrm{kg}$ per minute) was used to prevent ventricular fibrillation and to maintain the heart rate at 60 to 100 $\mathrm{bpm}$. Consistent with aseptic surgical processes, the chest was opened through the fourth intercostal space along the left border of the sternum. The pericardium was cut, and the heart was exposed. Proper ischemic conditioning was established through two-step ligation (Mu et al., 2009). Briefly, the LAD was ligated with a prolene suture just distal to the first diagonal branch. The slipknot was released after $50 \mathrm{~min}$. The thoracic cavity was closed layer by layer, and ECG monitoring was continued for $30 \mathrm{~min}$ after the operation. If ventricular fibrillation occurred, emergency treatment, such as electric defibrillation, intrathoracic pressure, or injection of lidocaine and adrenaline, was implemented; 
these cardioversion attempts were terminated if they were unsuccessful after more than $30 \mathrm{~min}$. All animals received analgesics (buprenorphine, $0.3 \mathrm{mg}$ ) and antimicrobial therapy (penicillin, $2400 \mathrm{IU})$ twice daily for 3 days after the operation. All animals were subjected to ECG monitoring and echocardiography in the preoperative and postoperative periods, and serum myocardial enzymes were monitored during the 24 -h postoperative period.

\section{Confirmation of the AMI Model}

Establishment of the AMI model was confirmed via three methods as follows: 1) ECG: The R wave amplitude was significantly increased in the limb lead, ST segments increased by $>0.5 \mathrm{mV}$ in the chest leads for more than $0.5 \mathrm{~h}$, and abnormal Q waves appeared $4 \mathrm{~h}$ later. 2) Emission computed tomography (ECT, USA, GE, INNOVA 2000): local defects and/or decreases were observed in the radioactive signal. 3) Pathology: under light microscopy, several findings related to the myocardial fibers were observed (congestion, edema, neutrophil infiltration, coagulation necrosis, nucleus degeneration, and disorganization). In addition, ultrasonic cardiograms and the levels of the spectrum of serum myocardial enzymes were evaluated according to a previous report (Figure 1, Table S3) (Munz et al., 2011).
The degree of AMI was assessed by gross specimens and ECT. There was no statistically significant difference in the degree of myocardial infarction in each group (Table S1 and S2).

\section{Preparation of Targeted Microbubbles}

Targestar SA (Targeson, Inc., San Diego, CA) is a targetable contrast agent with a streptavidin-coated surface to allow one-step coupling of biotinylated ligands that are suitable for molecular ultrasound imaging. Targeted microbubbles that specifically bind with SDF-1 were prepared according to the manufacturer guidelines. In brief, streptavidin-coated microbubbles were incubated with biotinylated rabbit anti-swine SDF-1 monoclonal antibody (BIOSS, Inc., Beijing, China). The mixture continued to be shaken lightly and was then incubated at room temperature for $20 \mathrm{~min}$ and centrifuged at $400 \mathrm{RPM}$ for $4 \mathrm{~min}$ to wash out unconjugated antibody (for rapid use within $4 \mathrm{~h}$ ). Then, the physical-chemical properties and the combined ratio of the prepared targeted ultrasound contrast agent were assessed using a fluorescence microscope and flow cytometer (Decano et al., 2011; Liu et al., 2014; Muramoto et al., 2014). The Targestar SA agent, which was not incubated with any antibody, was used as the nontargeted microbubbles.
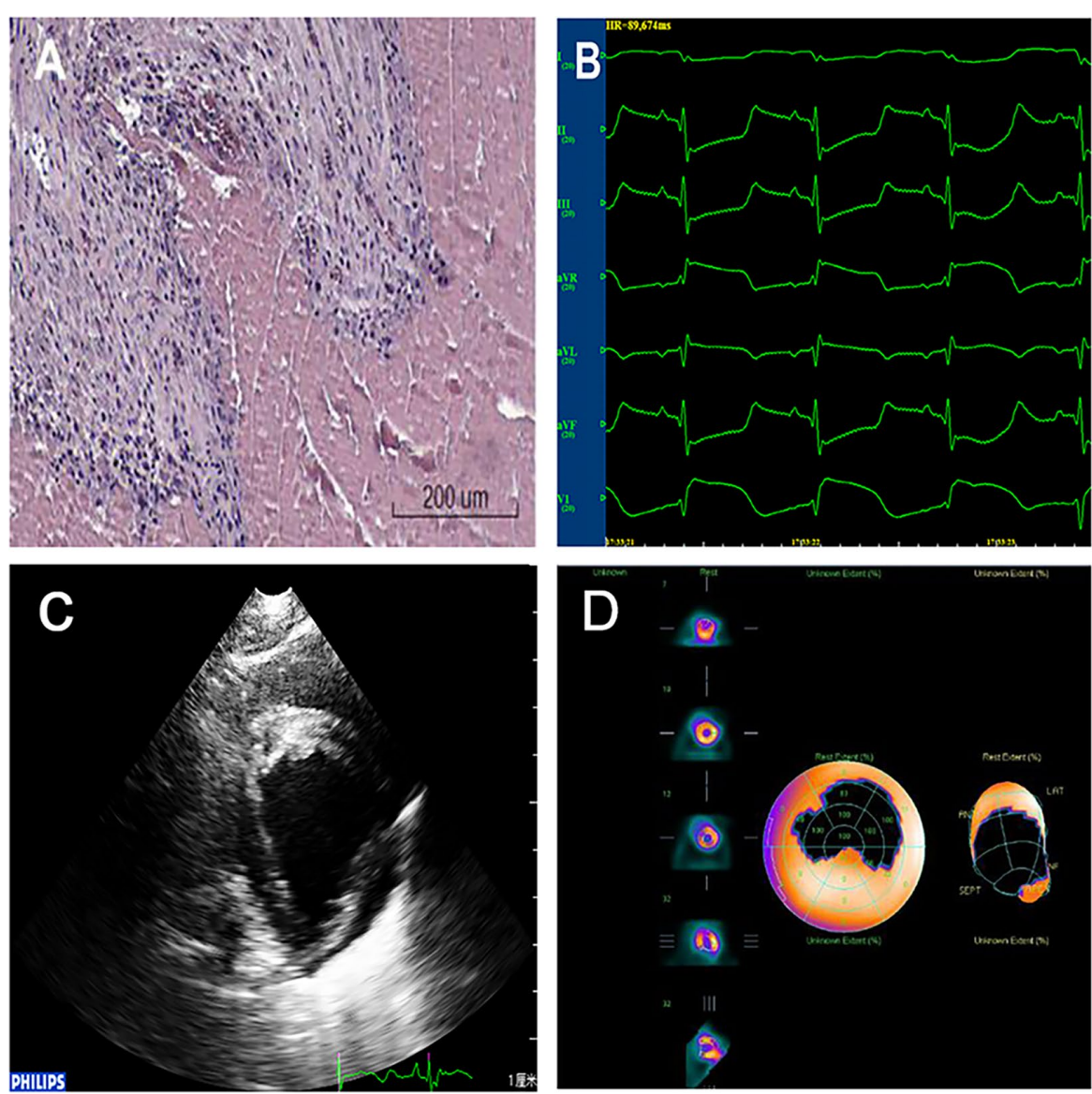

FIGURE 1 | Confirmation of the AMI model. (A) Pathology: myocardial fiber findings included congestion, edema, neutrophil infiltration, coagulation necrosis, nucleus degeneration, and organization. (B) ECG: ST segments increased by $>0.5 \mathrm{mV}$ in the chest leads. ECG, electrocardiogram; AMl, acute myocardial infarction. (C) Ultrasonic cardiograms: Segmental weakening of left ventricular wall motion on two-dimensional echocardiography. (D) ECT: Local defects and/or decreases were observed in the radioactive signal. 


\section{Myocardial Perfusion Parameter Analysis of Myocardial Contrast Echocardiography (MCE)}

The swine were subjected to anesthesia with ketamine $(10-15 \mathrm{mg} / \mathrm{kg}$, intramuscularly) and atropine $(25 \mu \mathrm{g} / \mathrm{kg}$, intramuscularly), and the venous channels of the marginal ear vein were opened. The swine were placed in a lateral position, the limbs were fixed, and the IE-33 ultrasound imaging instrument (cardiac probe model S5-1, $6 \mathrm{~Hz}$; American Philips; probe frequency, 1.8/3.6 MHz; mechanical index, 1.7/0.08) was applied. After satisfactory images were obtained, a contrast agent $(0.3 \mathrm{ml} / \mathrm{kg})$ was administered via intravenous bolus into the ear vein, followed by $5 \mathrm{ml}$ of saline. After myocardial imaging became stable, scintigraphy was triggered at the parasternal short-axis view of the papillary muscle. A highmechanical index (1.7) pulse was used to damage myocardial contrast agents. Then, the instrument automatically converted to a low mechanical index state (0.08). To facilitate observation of the contrast agents as they refilled the region of interest (ROI), dynamic images were recorded starting at the time of contrast agent injection and terminating upon the agent's clearance. All MCE images were analyzed by two experienced doctors using a double-blind Q-Lab workstation (Philips ultrasound, version 9.0). The ROI was set in the perfusion defect at the papillary muscle level. The software automatically recorded the refill time and the intensity curve of the contrast agent. Based on this analysis, the values of A (plateau intensity with respect to the myocardial blood volume), $\beta$ (refill rate with respect to the velocity of myocardial blood flow), and $A \times \beta$ (with respect to myocardial blood flow) as well as the fitting function $Y=\mathrm{A} \times\left(1-\mathrm{e}^{-\beta \mathrm{t}}\right)$ were determined (Figure 2) (Yang et al., 2013).

\section{Sampling Methods}

After contrast agent analysis and image acquisition, all animals were intravenously premedicated with midazolam hydrochloride and were then anesthetized and euthanized by an intravenous overdose of sodium thiopental and a saturated solution of potassium chloride. The myocardial papillary muscle tissue at the left ventricular short axis was removed, and the infarcted areas in the experimental group animals appeared white; the corresponding myocardial tissue in the control group was also removed.

\section{Quantitative Real-Time Polymerase Chain Reaction (qRT-PCR)}

Myocardial tissues were isolated, dissected, frozen in liquid nitrogen and stored at $-80^{\circ} \mathrm{C}$ until use. Total RNA was extracted using TRIzol reagent (Invitrogen Life Technology, USA) in accordance with the manufacturer's instructions. The quality of the isolated RNA was evaluated based on the ratio of A260/A280 and gel electrophoresis. Reverse transcription was performed at $37^{\circ} \mathrm{C}$ for $5 \mathrm{~min}$, at $42^{\circ} \mathrm{C}$ for $60 \mathrm{~min}$, and at $70^{\circ} \mathrm{C}$ for $10 \mathrm{~min}$ using a PrimeScript RT reagent kit (AMV First Strand cDNA Synthesis Kit, SK2445). To quantify the expression of SDF-1, real-time PCR was performed using a SYBR Green kit (ABI SybrGreen PCR Master Mix) in accordance with the manufacturer's instructions. The following primers were used:

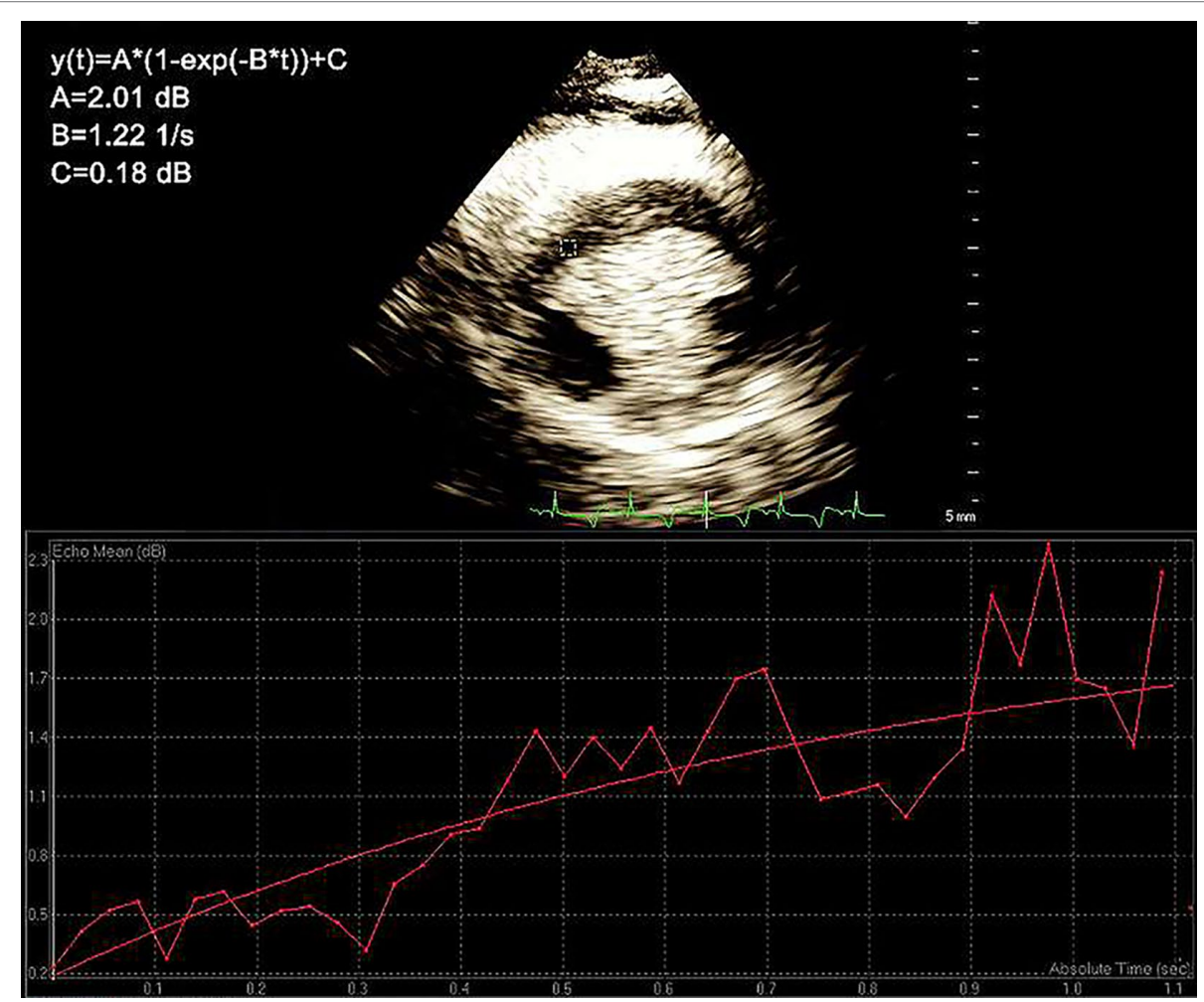

FIGURE 2 | The region of interest (ROI). The values of $A$ (plateau intensity with respect to the myocardial blood volume), $\beta$ (refill rate with respect to the velocity of myocardial blood flow), and $A \times \beta$ (with respect to myocardial blood flow) as well as the fitting function $Y=A \times\left(1-e^{-\beta t}\right)$ were determined. 
1) SDF-1 mRNA, forward 5'-ATGCCCTTGCCGATTCTTT-3' and reverse 5'-TATTGTTGCTCTTCAGCCGTG-3', with a PCR product of $116 \mathrm{bp}$, and 2) GAPDH mRNA, forward 5'-ATTTGG CTACAGCAACAGGGT-3' and reverse 5'-AAGTCAGGAGATG CTCGGTGT-3', with a PCR product of $172 \mathrm{bp}$. The conditions for real-time PCR were as follows: denaturation at $95^{\circ} \mathrm{C}$ for $2 \mathrm{~min}$, followed by 40 cycles of melting at $95^{\circ} \mathrm{C}$ for $10 \mathrm{~s}$ and annealing and extension at $60^{\circ} \mathrm{C}$ for $40 \mathrm{~s}$. The annealing temperatures for GAPDH and SDF- 1 were both $60^{\circ} \mathrm{C}$. The data were analyzed using the $2^{-\Delta \Delta \mathrm{CT}}$ method (Lou et al., 2014).

\section{Reproducibility Analysis}

Seven cases were randomly selected to assess intraobserver and interobserver agreement. The intraobserver assessment was performed with $>1$ week between analyses and with blinding to previous results. Interobserver agreement was assessed between two independent, blinded observers. The intraobserver reproducibility results were expressed as Pearson correlation coefficients. Interobserver reproducibility was determined using Bland-Altman analyses.

\section{Statistical Analysis}

All data are expressed as the means \pm standard deviations (SDs). The data were analyzed using SPSS version 17.0 (SPSS, Inc., Chicago, IL). An independent-samples $t$-test was used to compare the RT-PCR results and the myocardial perfusion parameters between the experimental and control groups. The differences in the RT-PCR results for the experimental groups were evaluated using one-way ANOVA. A paired $t$-test was used to compare the myocardial perfusion parameters between the $\mathrm{T}+\mathrm{T}$ and $\mathrm{T}+\mathrm{C}$ groups. Pearson correlation was used to analyze the correlations between the myocardial perfusion parameters and SDF- 1 in the $\mathrm{T}+\mathrm{T}$ and $\mathrm{T}+\mathrm{C}$ groups. A level of $P<0.05$ was considered statistically significant.

\section{RESULTS}

\section{Expression Characteristics and RT-PCR Comparison}

The results revealed that SDF-1 was expressed in the AMI experimental groups and the control group. The expression of SDF-l in the experimental groups increased more than that in the control group. After LAD ligation, the expression level of SDF-1 peaked at 1 week in the experimental groups. The differences between the experimental groups and the control group were statistically significant $(P<0.05)$, and the differences between the experimental groups were also statistically significant $(P<0.05)$ (Table 1 and Figure 3).

\section{Analysis of Myocardial Perfusion Parameters}

The myocardial perfusion parameters $(\mathrm{A}, \beta$, and $\mathrm{A} \times \beta)$ of the targeted contrast agent group ( $\mathrm{T}+\mathrm{T}$ group) and the normal contrast agent group ( $\mathrm{T}+\mathrm{C}$ group) were analyzed using $\mathrm{Q}-\mathrm{Lab}$ software at the parasternal left ventricular short axis of the papillary muscle. The differences between the experimental and control group were statistically significant $(P<0.05)$. All parameters decreased in the experimental groups, and the differences were statistically significant $(P<0.05)$. The differences between the $\mathrm{T}+\mathrm{T}$ and $\mathrm{T}+\mathrm{C}$ groups were also statistically significant $(P<0.05)$ (Table 2).

\section{Correlations Between the Myocardial Perfusion Parameters $(A, \beta$, and $A \times \beta)$ and the SDF-1 RT-PCR Results}

The correlations between the myocardial perfusion parameters $(A, \beta$, and $A \times \beta)$ and the SDF-1 RT-PCR results were analyzed, and the regression equations were established. The $\mathrm{A}$ and $\mathrm{A} \times \beta$ values were correlated with SDF- 1 in the $\mathrm{T}+\mathrm{C}$ group $(r=0.547$ and 0.506 , respectively; $P<0.05)$. The $\mathrm{A}, \beta$, and $\mathrm{A} \times \beta$ values were correlated with SDF-1 in the T $+\mathrm{T}$ group $(r=0.887,0.892$, and 0.942 , respectively; $P<0.05$ and $P<0.01$ ) (Table 3). Regression equations were established for the relationships between the $\mathrm{A}$, $\beta$, and $\mathrm{A} \times \beta$ values $(\mathrm{X})$ and SDF- $1(\mathrm{Y}): Y=0.699 X-0.6048, Y=$ $0.4698 X+0.3282$, and $Y=0.0945 X+0.6685\left(R^{2}=0.772,0.7957\right.$, and 0.8871 , respectively; $P<0.05$ and $P<0.01$ ) (Figures 4 and 5).

\section{Reproducibility}

The intraobserver and interobserver reproducibility results for all global strain continuous variables are presented in Figure 6. Bland-Altman analyses revealed the limits of agreement for $A, \beta$, and $\mathrm{A} \times \beta$ to be $-0.76 \%$ in $0.66 \%,-1.35 \%$ in $1.51 \%$, and $-6.8 \%$ in $5.7 \%$, respectively.

\section{DISCUSSION}

SDF-1 plays an important role in the healing of myocardial injury and promotes stem cell mobilization, migration, proliferation, survival, and differentiation. SDF-1 is expressed at different levels at different time points after myocardial infarction. Numerous studies have confirmed that SDF-1 is an important component of the microenvironments into which stem cells are transplanted. SDF-1 is also a potent chemotactic signal (Liekens et al., 2010; Marcello, 2010; Zaruba and Franz, 2010; Tang et al., 2011). Local SDF-1 expression near the site of myocardial infarction is closely related to the effects

TABLE 1 | The results of SDF-1 RT-PCR (2-( $(\Delta C$ Ct) $)$.

\begin{tabular}{|c|c|c|c|c|c|c|c|}
\hline Group & Control group & 1d & $3 d$ & $1 w$ & $2 w$ & $3 w$ & $4 w$ \\
\hline $\begin{array}{l}\text { SDF-1 RT-PCR } \\
(\mathrm{n}=3)\end{array}$ & $0.4162 \pm 0.0737$ & $0.636 \pm 0.0505^{\star \#}$ & $0.949 \pm 0.0661^{*}$ & $2.7079 \pm 0.6626^{\star \#}$ & $0.8200 \pm 0.1562^{* \#}$ & $1.2641 \pm 0.2580^{* \#}$ & $1.0793 \pm 0.2287^{\star \#}$ \\
\hline
\end{tabular}

Data are presented as the mean \pm standard deviation. " $P<0.05$ vs. the control group (sham operation). The differences in the experimental groups (different time points after acute myocardial infarction) were statistically significant $(" P<0.05)$. 
A

B
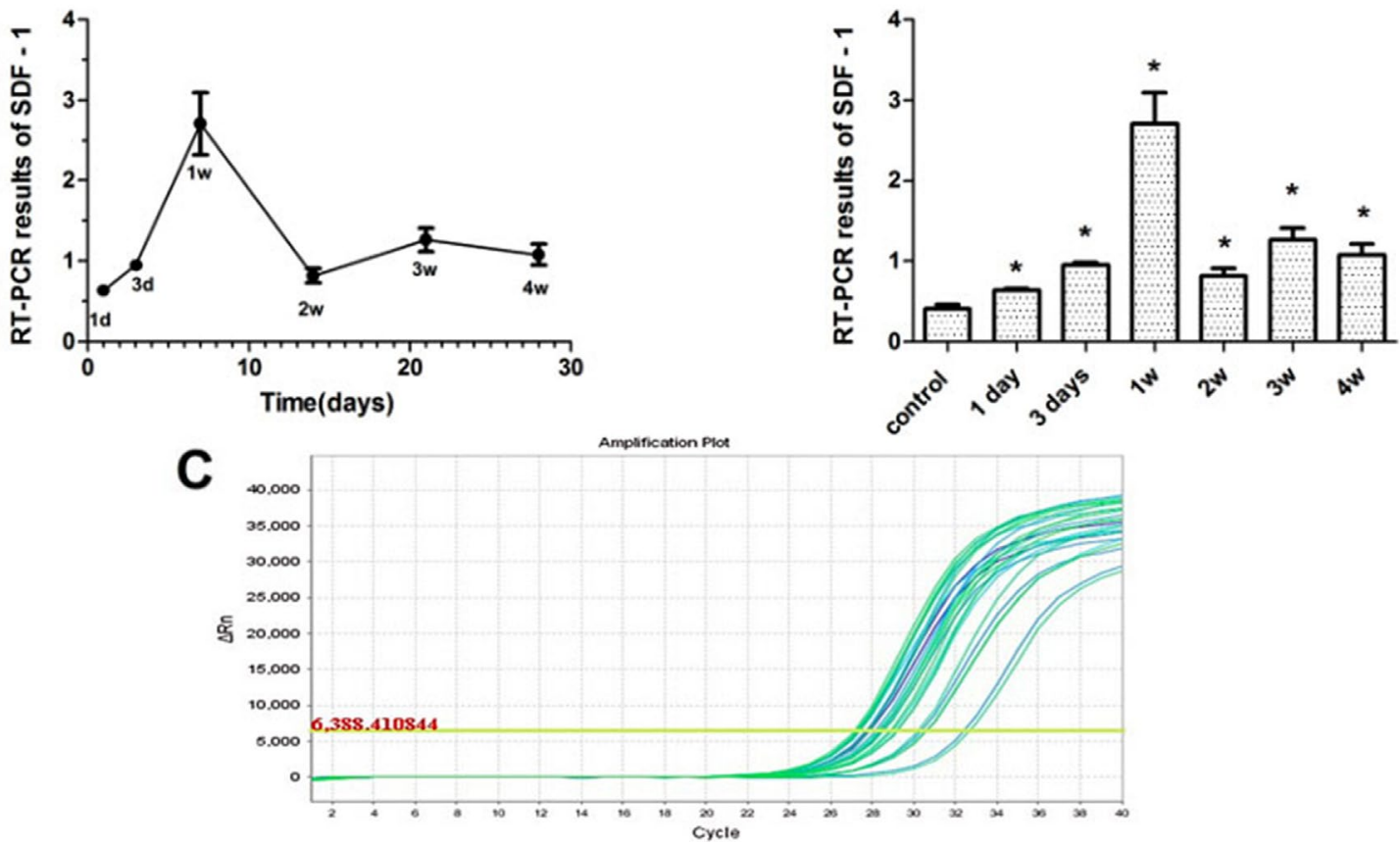

FIGURE 3 | The expression characteristics of SDF-1 in swine myocardium. (A) SDF-1 expression at various time points after myocardial infarction; expression peaked at 1 week in the experimental groups. (B) SDF-1 expression in the experimental and control groups. The expression of SDF-I in the experimental groups increased more than that in the control group. (C) The amplification curve of the SDF-1 gene. ${ }^{\star} P<0.05$.

TABLE 2 | Myocardial perfusion parameter values in the $T+T$ group, $T+C$ group, and control group $(A, \beta$, and $A \times \beta)$.

\begin{tabular}{|c|c|c|c|c|c|c|c|c|}
\hline Group & & $\begin{array}{c}\text { Control } \\
\text { group }\end{array}$ & $1 d$ & $3 d$ & $1 w$ & $2 w$ & $3 w$ & $4 w$ \\
\hline \multirow[t]{3}{*}{$\mathbf{T}+\mathbf{C}$ group } & $A(d B)$ & $6.48 \pm 0.39$ & $1.67 \pm 0.50^{\star}$ & $1.82 \pm 0.25^{\star}$ & $2.41 \pm 1.17^{\star}$ & $2.13 \pm 0.14^{\star}$ & $2.08 \pm 0.54^{\star}$ & $1.94 \pm 0.62^{*}$ \\
\hline & $\beta\left(s^{-1}\right)$ & $6.18 \pm 0.21$ & $1.91 \pm 0.23^{\star}$ & $1.44 \pm 0.70^{\star}$ & $1.63 \pm 0.05^{\star}$ & $0.82 \pm 0.15^{\star}$ & $1.03 \pm 0.17^{\star}$ & $0.79 \pm 0.29^{*}$ \\
\hline & $\mathrm{A} \times \beta(\mathrm{dB} / \mathrm{s})$ & $40.13 \pm 3.49$ & $3.25 \pm 1.35^{\star}$ & $2.72 \pm 1.48^{\star}$ & $3.95 \pm 1.93^{*}$ & $1.74 \pm 0.37^{\star}$ & $2.20 \pm 0.92^{\star}$ & $1.42 \pm 0.15^{\star}$ \\
\hline \multirow[t]{3}{*}{$\mathbf{T}+\mathbf{T}$ group } & $\mathrm{A}(\mathrm{dB})$ & $6.41 \pm 0.38$ & $2.36 \pm 0.24^{*} \#$ & $1.96 \pm 1.30^{\star \#}$ & $4.31 \pm 1.14^{\star \#}$ & $2.26 \pm 0.26^{\star \#}$ & $2.18 \pm 0.25^{\star \#}$ & $2.43 \pm 0.81^{\star \#}$ \\
\hline & $\beta\left(s^{-1}\right)$ & $6.16 \pm 0.16$ & $0.96 \pm 0.57^{\star \#}$ & $1.36 \pm 0.37^{\star \#}$ & $4.85 \pm 0.77^{\star \#}$ & $1.32 \pm 0.04^{\star \#}$ & $1.91 \pm 0.29^{* \#}$ & $1.28 \pm 0.56^{\star \#}$ \\
\hline & $\mathrm{A} \times \beta(\mathrm{dB} / \mathrm{s})$ & $39.55 \pm 2.95$ & $2.19 \pm 1.06^{* \#}$ & $2.69 \pm 0.80^{\star \#}$ & $21.15 \pm 7.85^{\star \#}$ & $3.44 \pm 0.31^{* \#}$ & $4.19 \pm 0.97^{\star \#}$ & $2.81 \pm 0.07^{\star \#}$ \\
\hline
\end{tabular}

Data are presented as the mean \pm standard deviation. ${ }^{*} P<0.05$ vs. the control group (sham operation). The differences between the $T+T$ group and the $T+C$ group were statistically significant ( $\left.{ }^{P} P<0.05\right) . T+T$ : targeted microbubbles ultrasound contrast agent. $T+C$ : normal ultrasound contrast agent. Control: sham operation.

TABLE 3 | Correlations between the myocardial perfusion parameters and SDF-1 mRNA expression.

\begin{tabular}{lccccccc}
\hline Group & \multicolumn{2}{c}{$\mathbf{A}(\mathbf{d B} / \mathbf{s})$} & \multicolumn{2}{c}{$\boldsymbol{\beta ( \mathbf { s } ^ { - 1 } )}$} & \multicolumn{2}{c}{$\mathbf{A} \times \boldsymbol{\beta}(\mathbf{d B} / \mathbf{s})$} \\
\cline { 2 - 7 } & $\boldsymbol{r}$ & $\boldsymbol{P}$ & $\boldsymbol{r}$ & $\boldsymbol{P}$ & $\boldsymbol{r}$ & $\boldsymbol{P}$ \\
\hline $\mathbf{T + C}$ & 0.547 & 0.019 & 0.181 & 0.473 & 0.506 & 0.032 \\
$\mathbf{T + T}$ & 0.887 & 0.000 & 0.892 & 0.000 & 0.942 & 0.000 \\
\hline
\end{tabular}

The correlations between the myocardial perfusion parameters $(A, \beta$, and $A \times \beta)$ and the SDF-1 RT-PCR results. The $A$ and $A \times \beta$ values were correlated with SDF-1 in the $T+C$ group $(r=0.547$ and 0.506 , respectively; $P<0.05)$. The $A, \beta$, and $A \times \beta$ values were correlated with SDF- 1 in the $T+T$ group $(r=0.887,0.892$, and 0.942, respectively; $P<0.05$ and $P<0.01) . T+T$ : targeted microbubbles ultrasound contrast agent. $T+C$ : normal ultrasound contrast agent. of stem cell transplantation. Determining prognosis for myocardial infarction requires recording of the time at which SDF-1 expression peaks (Huber et al., 2011; Wang et al., 2012; Schuh et al., 2014). As shown here, SDF-1 expression in the infarcted myocardial tissues were increased at various time points after AMI. The expression peaked at 1 week and then decreased. Studies investigating variations in the expression of SDF- 1 after myocardial infarction have yielded differing results. Munz et al. (2011) found that SDF-1 expression peaks at 1 week after myocardial infarction, which is consistent with the current results. However, Boyle et al. (2011) observed a temporary decline in SDF-1 expression shortly after myocardial infarction. Askari et al., (2003) detected SDF-1 expression at $1 \mathrm{~h}$ and 1 day after myocardial infarction but not at 1 


\section{A}

D
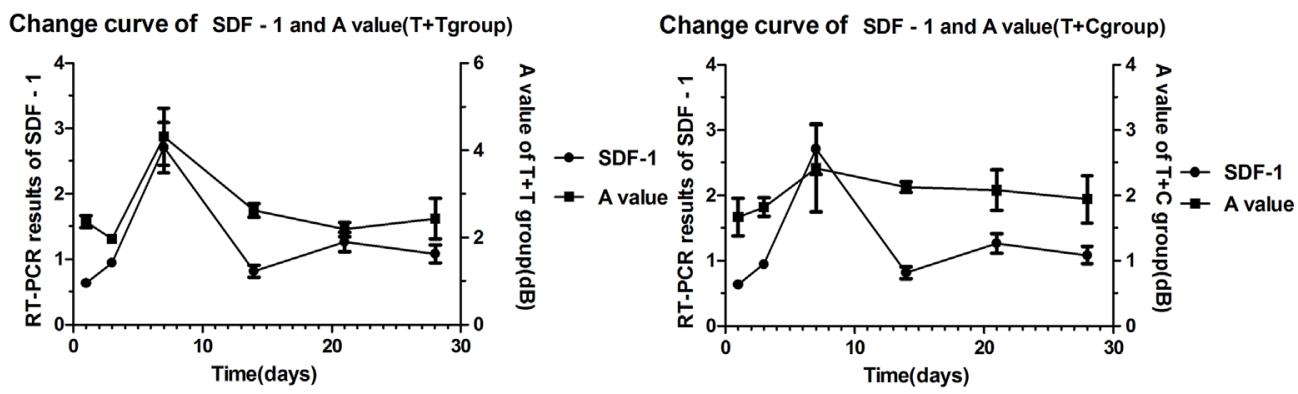

B

E

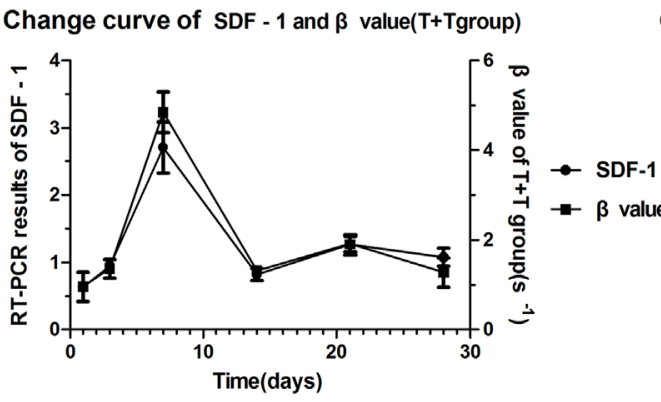

Change curve of SDF -1 and $\beta$ value(T+Cgroup)

C

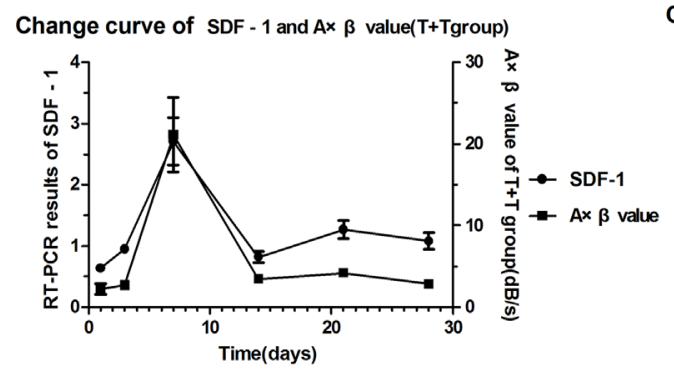

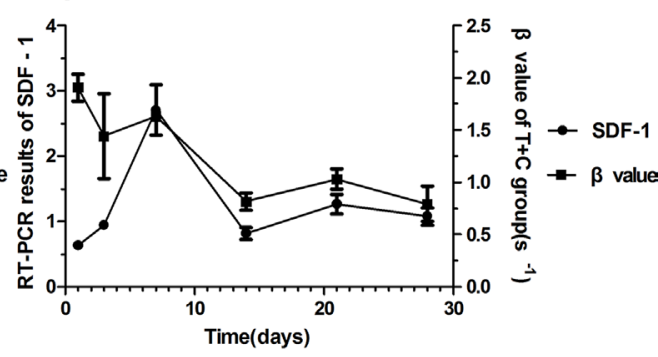

$\mathbf{F}$

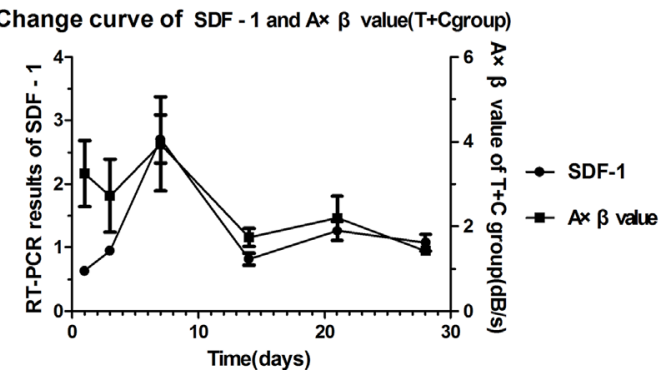

FIGURE 4 | The trend curves for SDF-1 and the myocardial perfusion parameters. (A) (B) (C) The trend curves for SDF- 1 and the A, $\beta$, and A $\times \beta$ values in the T $+\mathrm{T}$ group. (D) (E) (F) The trend curves for SDF-1 and the $A, \beta$, and $A \times \beta$ values in the $T+C$ group.

or 4 weeks after myocardial infarction or in a sham group. Abbott et al. (2004) reported that SDF-1 expression increases 1 day after myocardial infarction, peaks at 2 days, and remains relatively high during the 2 weeks following myocardial infarction, finally returning to normal levels by 3 weeks after infarction. Ma et al. (2005) observed a peak in SDF-1 expression 1 day after myocardial infarction, followed by a gradual decrease and a return to normal levels after 2 weeks. The discrepancies in these results may be due to the differences in the experimental animals, sampling methods, and detection methods used.

The results of this study indicated that changes in the periodic variation of the SDF-1 content were more prominent in the $\mathrm{T}+$ $\mathrm{T}$ group than those in the $\mathrm{T}+\mathrm{C}$ group. The myocardial perfusion parameters $(A, \beta$, and $A \times \beta)$, which reflect the perfusion of myocardial microcirculation, exhibited a correlation with the relative quantitative SDF-1 PCR results. These results demonstrated that the targeted ultrasound contrast agent was more effective than the general agent for the noninvasive in vivo evaluation of the dynamic changes in SDF-1, and this improved performance may be due to the targeted microbubbles containing SDF-1 monoclonal antibody. These microbubbles can specifically bind to SDF-1, causing the targeted myocardial contrast agent to exhibit stronger specific affinity for the infarcted myocardia. The $\mathrm{A} \times \beta$ value of the $\mathrm{T}+\mathrm{T}$ group and the relative quantitative SDF-1 PCR results were used to establish the regression equations. The results indicated that the $A \times \beta$ value was more accurate than the other indices in the noninvasive in vivo evaluation of dynamic changes in SDF- 1 . The $\mathrm{A} \times \beta$ value is expected to become the most commonly used quantitative parameter for evaluating changes in SDF-1 expression over time and facilitates the quantitative analysis of SDF-1 levels after myocardial infarction. 


\section{A}

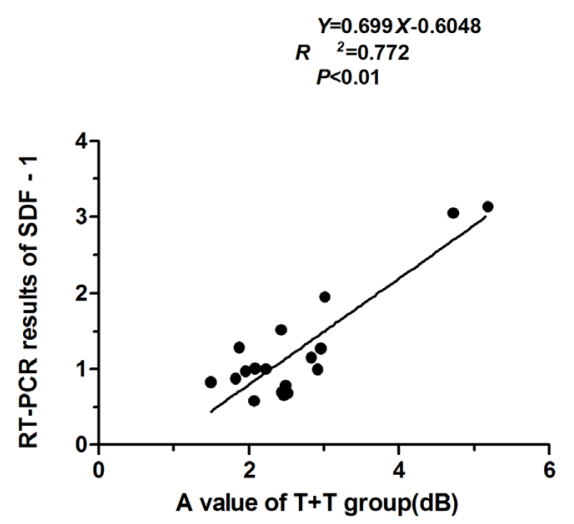

C

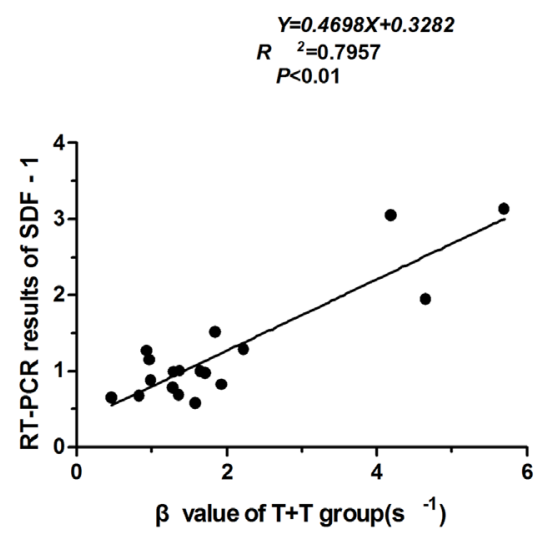

$\mathbf{E}$

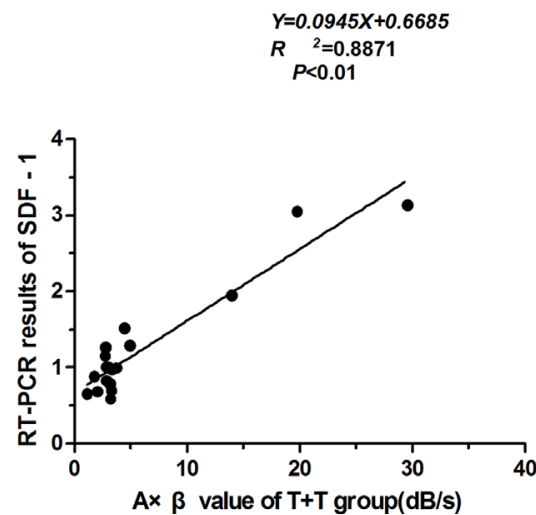

B
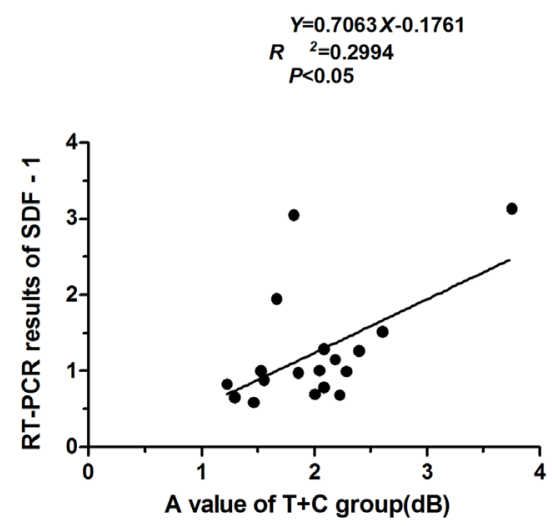

D

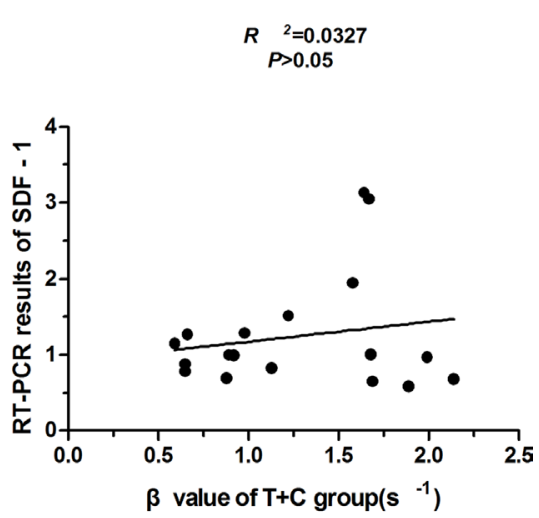

$\mathbf{F}$

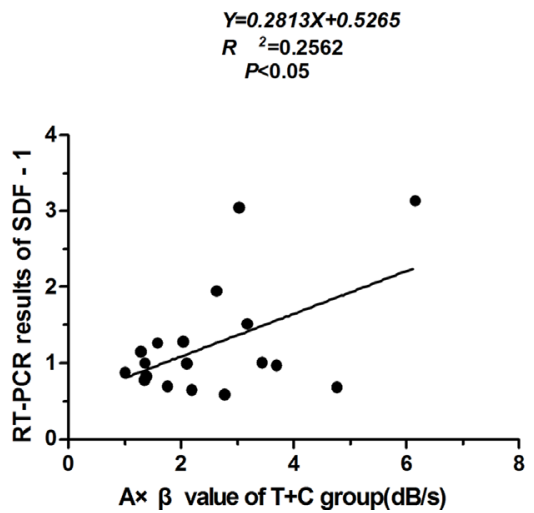

FIGURE 5 | Correlations between the myocardial perfusion parameters (A, $\beta$, and A $\times \beta$ ) and the SDF-1 RT-PCR results. (A) (B) (C) The A, $\beta$, and Ax $\beta$ values were correlated with SDF-1 in the $T+T$ group $(r=0.887,0.892$, and 0.942 , respectively; $P<0.05$ and $P<0.01)$. Regression equations were established for the relationships between the $A, \beta$, and $A \times \beta$ values $(X)$ and SDF-1 (Y). (D) (E) (F) The $A$ and $A \times \beta$ values were correlated with SDF-1 in the $T+C$ group $(r=0.547$ and 0.506, respectively; $P<0.05)$. Regression equations were established for the relationships between the $A$ and $A \times \beta$ values $(X)$ and $S D F-1(Y)$. $T+T$ : targeted microbubble ultrasound contrast agent. $T+C$ : nontargeted control microbubbles. 
A

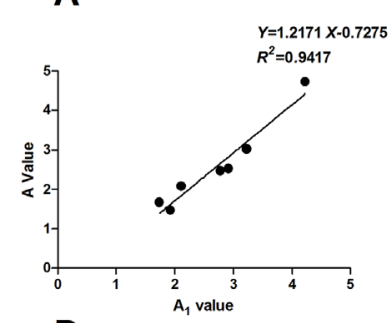

D

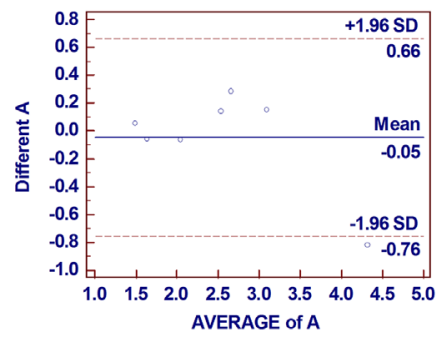

B

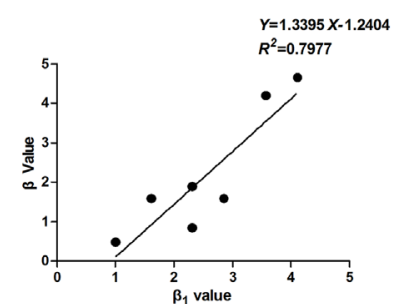

E

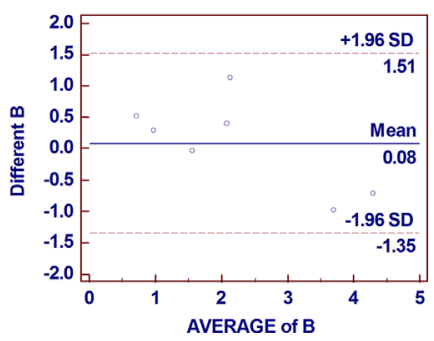

C
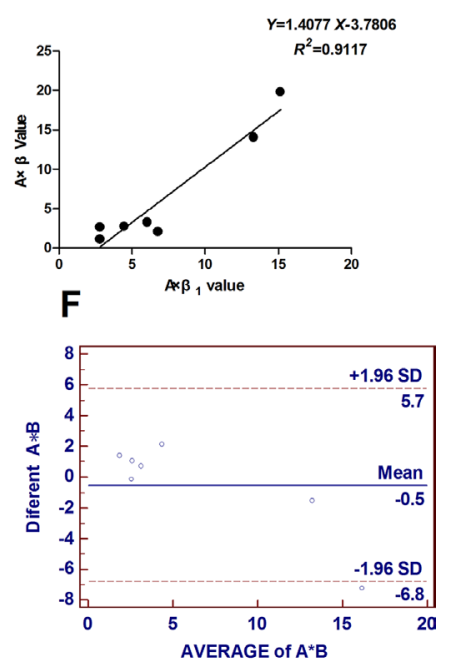

FIGURE 6 | Reproducibility analysis: seven cases were randomly selected to assess intraobserver and interobserver agreement. (A) (B) (C) Intraobserver reproducibility results expressed as Pearson correlation coefficients. (D) (E) (F) Interobserver reproducibility results obtained from Bland-Altman analyses. Bland-Altman analyses revealed the limits of agreement for $A, \beta$ and $A \times \beta$ to be $-0.76 \%$ to $0.66 \%,-1.35 \%$ to $1.51 \%$, and $-6.8 \%$ to $5.7 \%$, respectively. $B=\beta, A * B=A \times \beta$.

\section{CONCLUSIONS}

In summary, ultrasound molecular imaging using microbubbles targeting SDF-1 was found to facilitate the evaluation of changes in SDF-1 expression in vivo over time after AMI. The primary limitation of the study was the relatively small number of animals used.

\section{ETHICS STATEMENT}

The investigation complied with the Guide for the Care and Use of Laboratory Animals published by the US National Institutes of Health (NIH Publication No. 85-23, revised 1985) and the ARRIVE (Animal Research: Reporting In Vivo Experiments) guidelines. All animal procedures were approved by the Care of Experimental Animals Committee of the First Affiliated Hospital of Xinjiang Medical University, China. All animals were housed in an environmentally controlled facility with water ad libitum, and received humane care in compliance with institutional guidelines.

\section{AUTHOR CONTRIBUTIONS}

MW and RH were mainly involved in the experiment and were responsible for writing the manuscript. YY and LX participated

\section{REFERENCES}

Abbott, J. D., Huang, Y., Liu, D., Hickey, R., Krause, D. S., and Giordano, F. J. (2004). Stromal cell-derived factor-1alpha plays a critical role in stem cell recruitment to the heart after myocardial infarction but is not sufficient to induce homing in the absence of injury. Circulation 23 (110), 3300-3305. doi: 10.1161/01. CIR.0000147780.30124.CF in the experiments and data analysis. YM was mainly responsible for the experimental design and peer review.

\section{FUNDING}

This study was supported by a grant from the National Natural Science Foundation of China (30800480). Parts of this manuscript have previously been presented as abstract at the conference of American College of Cardiology (Yuming et al.).

\section{ACKNOWLEDGMENTS}

We would like to thank the Experimental Animal Center of Xinjiang Medical University for their technical laboratory assistance and proficiency in the animal surgeries. We also appreciate the advice provided by the Statistics Department of Xinjiang Medical University. We thank AJE for linguistic assistance during the preparation of this manuscript.

\section{SUPPLEMENTARY MATERIAL}

The Supplementary Material for this article can be found online at: https://www.frontiersin.org/articles/10.3389/fphar.2019.00899/ full\#supplementary-material et al. (2003). Effect of stromal-cell-derived factor 1 on stem-cell homing and tissue regeneration in ischaemic cardiomyopathy. Lancet 362, 697-703. doi: 10.1016/S0140-6736(03)14232-8

Boyle, A. J., McNiece, I. K., and Hare, J. M. (2010). Mesenchymal stem cell therapy for cardiac repair. Methods Mol. Biol. 660, 65-84. doi: 10.1007/ 978-1-60761-705-1_5 
Boyle, A. J., Yeghiazarians, Y., Shih, H., Ye, J., Sievers, R., Sievers, R., et al. (2011). Myocardial production and release of MCP-1 and SDF-1 following myocardial infarction differences between mice and man. J. Transl. Med. 9, 150-155. doi: 10.1186/1479-5876-9-150

Decano, J. L., Moran, A. M., and Ruiz-Opazo, N. (2011). Molecular imaging of vasa vasorum neovascularization via DEspR-targeted contrast-enhanced ultrasound micro-imaging in transgenic atherosclerosis rat model. Mol. Imaging Biol. 13, 1096-1106. doi: 10.1007/s11307-010-0444-4

Friedenstein, A. J., Deriglasova, U. F., Kulagina, N. N., Panasuk, A. F., Rudakowa, S. F., Luriá, E. A., et al. (1974). Precursors for fibroblasts in different populations of hematopoietic cells as detected by the in vitro colony assay method. Exp. Hematol. 2 (2), 83-92.

Ghadge, S. K., Muhlstedt, S., and Ozcelik, C. (2011). SDF-l alpha as a therapeutic stem cell homing factor in myocardial infarction. Pharmacol. Therapeut. 129 (1), 97-108. doi: 10.1016/j.pharmthera.2010.09.011

Huber, B. C., Brunner, S., Segeth, A., Nathan, P., Fischer, R., Zaruba, M. M., et al. (2011). Parathyroid hormone is a DPP-IV inhibitor and increases SDF-1driven homing of CXCR $4^{+}$stem cells into the ischaemic heart. Cardiovasc. Res. 90 (3), 529-537. doi: 10.1093/cvr/cvr014

Kuraitis, D., Ruel, M., and Suuronen, E. J. (2011). Mesenchymal stem cells for cardiovascular regeneration. Cardiovasc. Drugs Ther. 25 (4), 349-362. doi: 10.1007/s10557-011-6311-y

Liekens, S., Schols, D., and Hatse, S. (2010). CXCL12-CXCR4 axis in angiogenesis, metastasis and stem cell mobilization. Curr. Pharm. Des. 16 (35), 3903-3920. doi: $10.2174 / 138161210794455003$

Liu, H., Chang, S., Sun, J., Zhu, S., Pu, C., Zhu, Y., et al. (2014). Ultrasoundmediated destruction of LHRHa-targeted and paclitaxel-loaded lipid microbubbles induces proliferation inhibition and apoptosis in ovarian cancer cells. Mol. Pharm. 11 (1), 40-48. doi: 10.1021/mp4005244

Lou, L. X., Wu, A. M., Zhang, D. M., Wu, S. X., Gao, Y. H., Nie, B., et al. (2014). Yiqi Huoxue recipe improves heart function through inhibiting apoptosis related to endoplasmic reticulum stress in myocardial infarction model of rats. Evid. Based Complementary Altern. Med. 745919, 9. doi: 10.1155/2014/745919

Ma, J., Ge, J., Zhang, S., Sun, A., Shen, J., Chen, L., et al. (2005). Time course of myocardial stromal cell-derived factor 1 expression and beneficial effects of intravenously administered bone marrow stem cells in rats with experimental myocardial infarction. Basic Res. Cardiol. 100, 217-223. doi: 10.1007/ s00395-005-0521-z

MacArthur, J. W. Jr, Purcell, B. P., Shudo, Y., Cohen, J. E., Fairman, A., Trubelja, A., et al. (2013). Sustained release of engineered stromal cell-derived factor 1- $\alpha$ from injectable hydrogels effectively recruits endothelial progenitor cells and preserves ventricular function after myocardial infarction. Circulation 128, 79-86. doi: 10.1161/CIRCULATIONAHA.112.000343

Marcello, R. (2010). SDF-1 axis and myocardial repair. Am. J. Physiol. Heart Circ. Physiol. 299 (5), 307-308. doi: 10.1152/ajpheart.00876.2010

Mozaffarian, D., Benjamin, E. J., Go, A. S., Arnett, D. K., Blaha, M. J., Cushman, M., et al. (2016). Heart disease and stroke statistics-2016 update: a report from the American Heart Association. Circulation 133 (4), e38-e360. doi: 10.1161/ CIR.0000000000000350

Mu, Y., Meng, W., Rong, H., and Qi, S. (2015). In vivo ultrasound molecular imaging of SDF-1 expression in a swine model of acute myocardial infarction. J. Am. Coll. Cardiol. 66 (16), C254-C255. doi: 10.1016/j.jacc.2015.06.990

Mu, Y. L., Xie, Y. Y., and Wang, F. W. (2009). Protective effect of Methylamine Irisolidone, a novel compound, on acute myocardial ischemia in anesthetized dogs. J. Food Drug Anal. 17 (1), 11-16. doi: 10.6227/jfda

Munz, M. R., Faria, M. A., Monteiro, J. R., Aguas, A. P., and Amorim, M. J. (2011). Surgical porcine myocardial infarction model through permanent coronary occlusion. Comp. Med. 61 (5), 445-452. doi: 10.1186/2046-0481-64-12

Muramoto, T., Shimoya, R., Yoshida, K., and Watanabe, Y. (2014). Evaluation of the specific adsorption of biotinylated microbubbles using a quartz crystal microbalance. Ultrasound Med. Biol. 40 (5), 1027-1033. doi: 10.1016/j. ultrasmedbio.2013.11.011

Naaijkens, B. A., Niessen, H. W., Prins, H. J., Krijnen, P. A., Kokhuis, T. J., de Jong, N., et al. (2012). Human platelet lysate as a fetal bovine serum substitute improves human adipose-derived stromal cell culture for future cardiac repair applications. Cell. Tissue Res. 348 (1), 119-130. doi: 10.1007/s00441-012-1360-5
Naaijkens, B. A., van Dijk, A., Kamp, O., Krijnen, P. A., Niessen, H. W., and Juffermans, L. J. (2014). Therapeutic application of adipose derived stem cells in acute myocardial infarction: lessons from animal models. Stem Cell. Rev. Rep. 10 (3), 389-398. doi: 10.1007/s12015-014-9502-7

Oswald, J., Boxberger, S., Jorgensen, B., Feldmann, S., Ehninger, G., Bornhäuser, M., et al. (2004). Mesenchymal stem cells can be differentiated into endothelial cells in vitro. Stem Cells 22 (3), 377-384. doi: 10.1634/stemcells.22-3-377

Pfeffer, M. A., and Braunwald, E. (1990). Ventricular remodeling after myocardial infarction. Experimental observations and clinical implications. Circulation 81 (4), 1161-1172. doi: 10.1161/01.CIR.81.4.1161

Pfeffer, M. A., McMurray, J. J., Velazquez, E. J., Rouleau, J. L., Køber, L., Maggioni, A. P., et al. (2003). Valsartan, captopril, or both in myocardial infarction complicated by heart failure, left ventricular dysfunction, or both. N. Eng. J. Med. 349 (20), 1893-1906. doi: 10.1056/NEJMoa032292

Pittenger, M. F., and Martin, B. J. (2004). Mesenchymal stem cells and their potential as cardiac therapeutics. Circ. Res. 95 (1), 9-20. doi: 10.1161/01. RES.0000135902.99383.6f

Roger, V. L., Go, A. S., Lloyd-Jones, D. M., Benjamin, E. J., Berry, J. D., Borden, W. B., et al. (2012). Executive summary: heart disease and stroke statistics-2012 update: a report from the American Heart Association. Circulation 125 (1), 188-197. doi: 10.1161/CIR.0b013e31825e74db

Schuh, A., Konschalla, S., Kroh, A., Schober, A., Marx, N., Sonmez, T. T., et al. (2014). Effect of SDF-1 a on endogenous mobilized and transplanted stem cells in regeneration after myocardial infarction. Curr. Pharm. Des. 20 (12), 19641970. doi: $10.2174 / 13816128113199990443$

Song, G. X., Li, X. R., Zhang, F. X., and Zhang, L. Z. (2012). The occurrences of ventricular arrhythmia after acute myocardial infarction in a porcine model: comparison between ligation and occlusion. Chin. J. Card. Pacing Electrophysiol. 26 (3), 246-249. doi: 10.13333/j.cnki.cjcpe.2012.03.022

Tang, J. M., Wang, J. N., Zhang, L., Zheng, F., Yang, J. Y., Kong, X., et al. (2011). VEGF/SDF-1 promotes cardiac stem cell mobilization and myocardial repair in the infarcted heart. Cardiovasc. Res. 91 (3), 402-411. doi: 10.1093/ $\mathrm{cvr} / \mathrm{cvr} 053$

Wang, K., Zhao, X., Kuang, C., Qian, D., Wang, H., Jiang, H., et al. (2012). Overexpression of SDF-1a enhanced migration and engraftment of cardiac stem cells and reduced infarcted size via CXCR4/PI3K pathway. PLoS One 7 (9), e43922. doi: 10.1371/journal.pone.0043922

Won, Y. W., Patel, A. N., and Bull, D. A. (2014). Cell surface engineering to enhance mesenchymal stem cell migration toward an SDF-1 gradient. Biomaterials 35 (21), 5627-5635. doi: 10.1016/j.biomaterials.2014.03.070

Yang, C. H., Sheu, J. J., Tsai, T. H., Chua, S., Chang, L. T., Chang, H. W., et al. (2013). Effect of tacrolimus on myocardial infarction is associated with inflammation, ROS, MAP kinase and Akt pathways in mini-pigs. J. Atheroscler. Thromb. 20 (1), 9-22. doi: 10.5551/jat.14316

Yang, S. L., Mu, Y. M., Tang, K. Q., Jiang, X. K., Bai, W. K., Shen, E., et al. (2013). Enhancement of recombinant adeno-associated virus mediated transgene expression by targeted echo-contrast agent. Genet. Mol. Res. 12 (2), 1318-1326. doi: 10.4238/2013.April.25.3

Zaruba, M. M., and Franz, W. M. (2010). Role of the SDF-1-CXCR4 axis in stem cell-based therapies for ischemic cardiomyopathy. Expert Opin. Biol. Ther. 10 (3), 321-335. doi: 10.1517/14712590903460286

Zuk, P. A., Zhu, M., Ashjian, P., De Ugarte, D. A., Huang, J. I., Mizuno, H., et al. (2002). Human adipose tissue is a source of multipotent stem cells. Mol. Biol. Cell. 13 (12), 4279-4295. doi: 10.1091/mbc.e02-02-0105

Conflict of Interest Statement: The authors declare that the research was conducted in the absence of any commercial or financial relationships that could be construed as a potential conflict of interest.

Copyright (C) 2019 Wang, Hu, Yang, Xiang and Mu. This is an open-access article distributed under the terms of the Creative Commons Attribution License (CC BY). The use, distribution or reproduction in other forums is permitted, provided the original author(s) and the copyright owner(s) are credited and that the original publication in this journal is cited, in accordance with accepted academic practice. No use, distribution or reproduction is permitted which does not comply with these terms. 